\title{
Validation Effectiveness Of Develop Maintainability Allocation On Aircraft Mechanical Components
}

\author{
W.M.S. Wan Husain ${ }^{1}$, S. Aman Shah ${ }^{2}$ \\ ${ }^{1}$ Aerospace Section, Universiti Kuala Lumpur, Malaysian Institute of Aviation Technology, Selangor. \\ ${ }^{2}$ Avionics Section, Universiti Kuala Lumpur, Malaysian Institute of Aviation Technology. Selangor.
}

\begin{abstract}
Abstact. Maintainability Allocation is a process to identify the allowable maximum task time for each individual component. Consequently, this provides clear pictures to the designers to design and identify potential design improvement within allowable maintenance allocation time limits. During the design process elements such as missteps or misapplications most commonly occur. Here, the authors propose having the maximum target for each individual maintainability component. The main objective of this paper is to present the validation process of developed Maintainability Allocation to potentially eliminate previous problems. The process of validation begins with analysed all the data collected from Service Difficulty Reports (SDR) for selected aircraft. This is to understand the problems from existing aircraft before a new design is proposed through the process of Maintainability Allocation prediction. The validation processes have discovered the importance of utilising historical information such as feedback information. The second area is looking at the element of quantifying the data collected from aircraft feedback information which contains various types of information that could be used for future improvement. Validation process shows that feedback information has helped to identify the critical and sensitive components that need more attention for further improvement. The study shows that the aircraft maintenance related feedback information systems analyses were very useful for deciding maintainability effectiveness; these include planning, organising maintenance and design improvement. There is no doubt that feedback information has the ability to contribute an important role in design activities. The results also show that maintainability is an important measure that can be used as a guideline for managing efforts made for the improvement of aircraft components.
\end{abstract}

\section{Introduction}

The validation process presented in this paper is performed based on the author visit to approved Maintenance Repair Organisation (MRO) Company in UK. The BAe $146-300$ is one of the aircraft available for author to study and visualise the aircraft components. Figure 1 show the pictures of BAe $146-$ 300 aircraft landing gear used in this study for the purpose of the validation process.

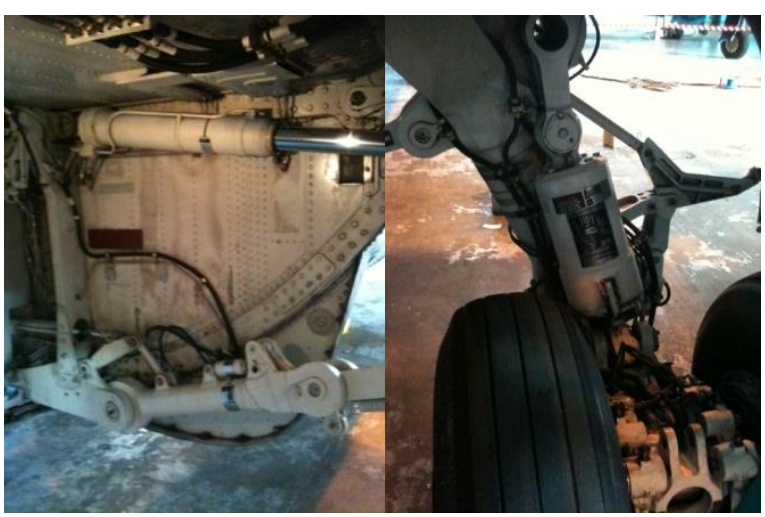

Figure 1 BAe 146 - 300 aircraft landing gear (Source: Author)

\section{Service Difficulty Reports (SDR) - Landing Gear}

The first process was to understand the SDR historical data related to BAe 146 . The historical data and information were analysed for a period of twenty years (1990 - 2009). BAe 146 SDR started from 1992 and increased up to 1998 with various types of part conditions. In total there are 1,688 SDR and the trend is illustrated in Figure 2. The author decided to perform the SDR analysis up to twenty years because the data available for ten years (i.e. 2000 - 2009) are not enough for this research to make appropriate judgements. By extending the SDR analyses period this study expected to be able to understand and undertake necessary action to identify the most suitable aircraft mechanical components. The results show increasing SDR reports in the first nine years (i.e. 1990 - 1998) however, begins to decrease in the following years beginning in 1999. This could be caused by the decrease in demand for this of type aircraft and/or the invention of new types of aircraft that could be more reliable and efficient.

The first part in the analysis study is to identify which part names of the aircraft cause the greatest number of SDR. Figure 3 illustrates the percentage distribution of failed part condition for both BAe $146-200$ and -300 . Landing gear has contributed the highest percentage of SDR reports with $18.18 \%$, followed by Engine (Turbine/Turboprop) with $15.91 \%$, and Flight Control System with $10.61 \%$. As illustrated in Figure 3 with the total number of SDR for BAe 146 is 132.

Because the landing gear systems show the highest contribution to SDR for BAe 146, the author carried out further analyses within landing gear systems to have a better understanding. There total of 100 SDR reports are collected for BAe 146 Landing gear system. Figure 4 illustrate the percentage distribution for BAe 146 
Landing gear system in accordance with part conditions. The most reported part condition include cracked contributed $24.0 \%$ SDR reports, failed with $20.0 \%$ SDR reports, and corroded with $10.0 \%$ of SDR reports. Other types of part condition are faulty with 7.0 SDR reports and followed by damaged and broken which each one contributed 5.0\% SDR reports. Table 1 show the detail SDR discrepancy statement which offers and useful to the designer to understand the scenario and condition why the components are failed.

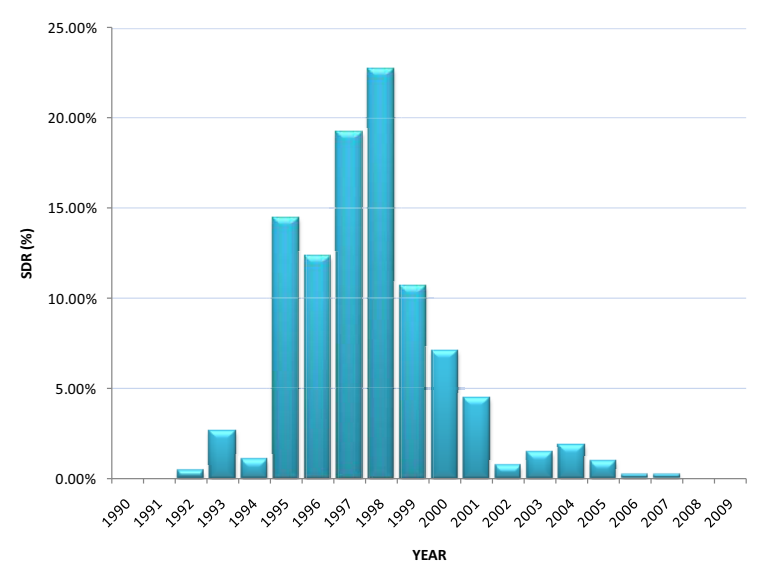

Figure 2 The trend of SDR analyses for all types of BAe 146

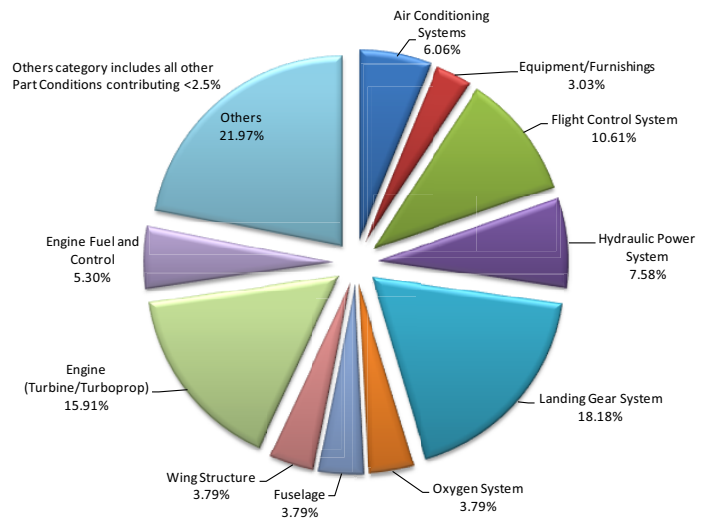

Figure 3 Failed Part Condition percentage distribution for BAe 146 in accordance with JASC Code

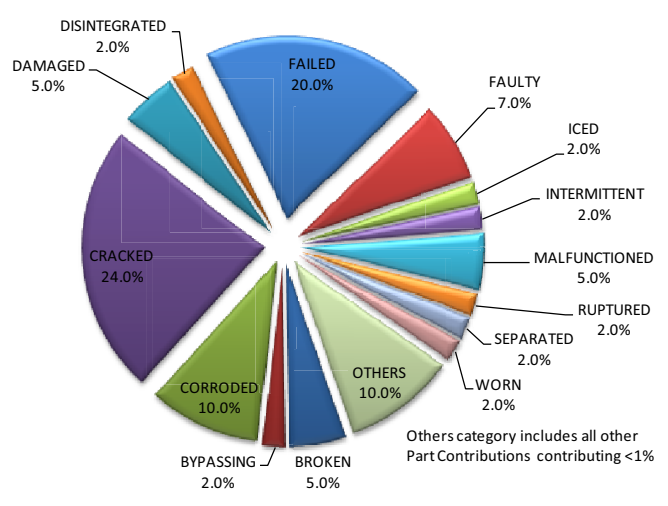

Figure 4 Percentage distributions for BAe 146 in accordance with Part Conditions
Table 1 Landing gear system SDR discrepancy statement in accordance with Part Condition [1]

\begin{tabular}{|c|c|c|c|}
\hline 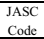 & \begin{tabular}{|c|c|c|} 
Part \\
Condition
\end{tabular} & Part Location & Discrepancy \\
\hline 3260 & FALLED & LT MLG & $\begin{array}{l}\text { (AUS) LEFT MAIN LANOING GEAR UPIOCK ACTUATOR HOSE ASSEMBLY RUPTURED } \\
\text { HOSE LEAKING FROM END FITTING. LOSS OF GREEN' SYSTEM HYDRAUUCS. }\end{array}$ \\
\hline 3260 & FAILED & RT MLG & $\begin{array}{l}\text { LANDING GEAR HANOI REQ OVERRIDE ON GEAR RETRACTION AFTER TAKEOFF } \\
\text { FROMORD. REMOVED AND REPLACED RIGHT MG WEIGHT OFF HARNESS ASSY. }\end{array}$ \\
\hline 3230 & FALLED & NLG & $\begin{array}{l}\text { NOSE LANOING GEAR RETRACTINN ACTUAAOR FEXIBLE HYDRAULIC HOSE } \\
\text { RUPTURED. LOSS Of GREEN SYSTEM HYDRAUUC FLUID. }\end{array}$ \\
\hline 3297 & FALLED & LT & $\begin{array}{l}\text { UPON GEAR RETRACTION LEFT MAIN GEAR SHOWS RED UNSAFE WITH GEAR HAN } \\
\text { LT ON. REMOVED AND REPLACED LEFT MLG DOOR UPIOCK SENSOR HARNESS. }\end{array}$ \\
\hline 3234 & FAlLED & MLG & LANDING GEAR SELECTOR LEVER WOULD NOT MOVE TO THE UP" POSITION. \\
\hline 3234 & FAILED & $\begin{array}{c}\text { LANDING } \\
\text { GEAR }\end{array}$ & $\begin{array}{l}\text { GEAR FAILED TO EXTEND WHEN SELECTED. WENT TO EMERGENCY AND GEAR } \\
\text { EXTENDED. LANDED WITHOUT INCIDENT. SENT REPLACEMENT VALVE AND } \\
\text { ACTUATOR TO DEN. }\end{array}$ \\
\hline
\end{tabular}

In order to have accurate understanding, the author carried out further analyses to identify which part name mostly affected and received the most SDR reports. Figure 5 illustrate the types of part name contributed the most SDR reports. Pin, actuator, and wheel contributed the most SDR reports which each one of the part names contributed $15.0 \%$ for the pin, $8.0 \%$ for wheel, and $7.0 \%$ for actuator.

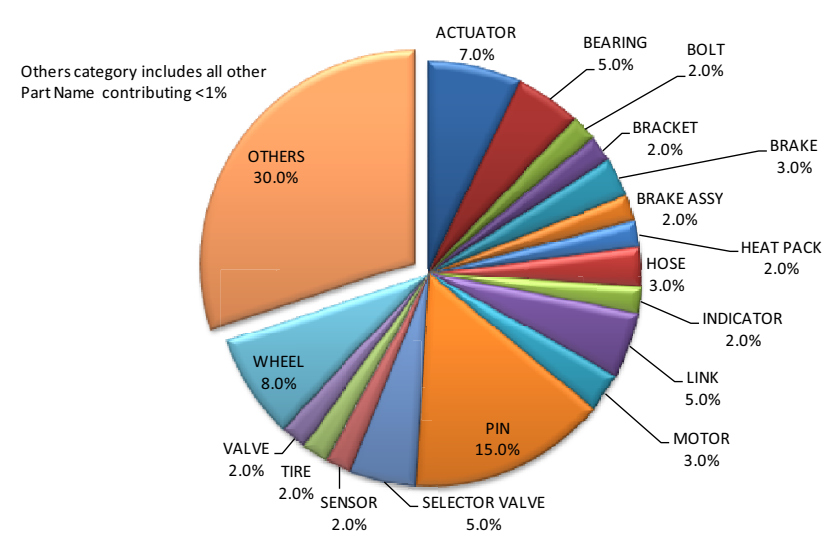

Figure 5 Percentage distribution for BAe 146 in accordance with Part Name

Meanwhile, in Table 2 below shows the detail SDR discrepancy statement for BAe 146 Landing gear system in accordance with the part name. Most of the problems related to SDR is cracked which is also commonly found during Magnetic Partcile Inspection process. Based on this result, the author found that the landing gear system is a part name for the validation process. Table 3 shows the list of information sources of how the validation process was performed.

Table 2 Landing gear system SDR discrepancy statement in accordance with Part Name [1]

\begin{tabular}{|c|c|c|c|}
\hline $\begin{array}{l}\text { JASC } \\
\text { Code }\end{array}$ & Part Name & Part Location & Discrepancy \\
\hline 5230 & PIN & NIG & $\begin{array}{l}\text { (AUS) NOSE LANDING GEAR RETRACTIONJACK ATTAOMNT PIN CRACKED. FOUND) } \\
\text { DURING MAGNETIC PARTICLE INSPECTION CRACK LENGTH } 19.05 \mathrm{MM}(0.75 \text { INCH) }\end{array}$ \\
\hline 1230 & PIN & NLG & $\begin{array}{l}\text { (AUS) NOSE LANDING GEAR RETRACTIONJACK ATTAOMNT PIN CRACKED FOUND } \\
\text { DURING MAGNETIC PARTICLE INSPECTION. CRACK LENGTHS } 19.05 \text { MM AND } 117 \text { MM }\end{array}$ \\
\hline 3230 & PIN & NIG & \begin{tabular}{|l|} 
(AUS) NOSE LANDING GEARRETRACTION JACK ATTACHE NT PIN CRACKED.FOUND \\
DURING MAGNETIC PARTIIE INSPECTION. CRACK LENGTH 11875 MM $<0.625$ INCH)
\end{tabular} \\
\hline 3230 & PIN & NIG & $\begin{array}{l}\text { (AUS) NOSE LANDINGGEAR RETRACTIONJACK ATTACHMENT PIN CRACKED.FOUND } \\
\text { DURING MAGNETIC PART XIE INSPECTION. CRACK LENGTH } 76.2 \mathrm{KM} \text { (3 INCHES). }\end{array}$ \\
\hline 3213 & PIN & $\mathrm{MjG}$ & 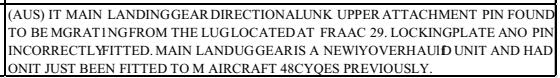 \\
\hline
\end{tabular}


Table 3 Summary of information sources for BAe 146 - 300 Landing Gear validation

\begin{tabular}{|l|l|l|}
\hline No & \multicolumn{1}{|c|}{$\begin{array}{c}\text { Data and } \\
\text { Information }\end{array}$} & $\begin{array}{l}\text { Approved Aircraft } \\
\text { Maintenance Manual; and } \\
\text { Analysed FAA Service } \\
\text { Difficulty Reports [2] }\end{array}$ \\
\hline $\mathbf{1}$ & List of Components \\
\hline $\mathbf{2}$ & List of Failure Rate & $\begin{array}{l}\text { Non-electronic Part } \\
\text { Reliability Data (NPRD) } \\
1995[3]\end{array}$ \\
\hline $\mathbf{3}$ & $\begin{array}{l}\text { Maintainability } \\
\text { Predictions }\end{array}$ & $\begin{array}{l}\text { MIL-HDBK-472[4]; } \\
\text { DOD-HDBK-791[5]; } \\
\text { CAAIP [6] }\end{array}$ \\
\hline $\mathbf{4}$ & $\begin{array}{l}\text { Maintainability } \\
\text { Prediction; } \\
\text { Checklist C }\end{array}$ & $\begin{array}{l}\text { Developed approach by } \\
\text { author }\end{array}$ \\
\hline $\mathbf{5}$ & $\begin{array}{l}\text { Maintainability } \\
\text { Allocation }\end{array}$ & $\begin{array}{l}\text { Improved modules and } \\
\text { scores by author }\end{array}$ \\
\hline $\mathbf{6}$ & $\begin{array}{l}\text { Process } \\
\text { Validation }\end{array}$ & $\begin{array}{l}\text { As shown in Integrated } \\
\text { Methodology, Chapter 6 }\end{array}$ \\
\hline
\end{tabular}

\section{Maintainability Allocation - BAE 146 - 300 Landing gear}

Based on the methodology developed, the authors extended maintainability allocation method was used. The maintainability allocation was the next process to be performed, using extended modules and score values developed by the author. The maintainability allocation was predicted based on Mean Time to Repair (MTTR). The MTTR values can be predicted based on historical data, and/or the decision from top level management. For the purpose of comparison, the author used two different approaches. One of the approaches is to utilise the 1.00 hour as an MTTR value as per advised by industrial experts. The result of the maintainability allocation is shown in Table 4.

The rest of the prediction values were calculated by using the existing methodology developed by Chipchak [7] and by using new module and score improved by the author. There are some listed components requiring more than one module. Component number 4: Brake Assembly for example, required two modules, namely electromechanical equipment and mechanical structures, with mechanisms for which each module offered 3 and 8 score values respectively. Therefore, allocation of the final score values for the brake assembly is by average, i.e. 5.5 hours.
Table 4 Maintainability allocation based on MTTR = 1.00

\begin{tabular}{|c|l|c|}
\hline No & Components & $\begin{array}{c}\text { Maintenance Allocation Time } \\
\text { MTTR }=1.00 \text { hour }\end{array}$ \\
\hline 1 & Actuator & 0.85 \\
\hline 2 & Antiskid & 0.85 \\
\hline 3 & Brake & 1.32 \\
\hline 4 & Brake Assembly & 1.08 \\
\hline 5 & Connector & 0.85 \\
\hline 6 & Control Unit & 0.75 \\
\hline 7 & Hydraulic & 0.85 \\
\hline 8 & Proximity Sensor & 1.13 \\
\hline 9 & Proximity Switch & 1.13 \\
\hline 10 & Selector Valve & 0.85 \\
\hline 11 & Sensor & 0.94 \\
\hline 12 & Steering & 1.13 \\
\hline 13 & Structure & 1.13 \\
\hline 14 & Strut & 1.13 \\
\hline 15 & Switch & 0.85 \\
\hline 16 & Tire & 1.13 \\
\hline 17 & Uplock Switch & 0.85 \\
\hline IS & V-Belt & 1.13 \\
\hline 19 & Warning Light & 0.85 \\
\hline 20 & Warning Systems & 1.13 \\
\hline 21 & Wheel & 1.13 \\
\hline 22 & Wire & 0.85 \\
\hline 23 & Wire Harness & 0.85 \\
\hline & & \\
\hline
\end{tabular}

\section{Maintainability Prediction - BAE 146 - Landing Gear}

The maintainability full scale prediction was begun with maintainability task time predictions by using MILHDBL-472, procedure III. The detailed process of task time predictions has been described in the maintainability prediction chapter. MIL-HDBK-472, procedure III consists of three main elements: Checklist A: Design; Checklist B; Facilities; and Checklist C: Human Factors. Maintainability prediction was performed by using checklists $\mathrm{A}$ and $\mathrm{B}$ questions. To ensure the score values were accurately identified, additional references were used by the author such as Civil Aircraft Airworthiness Information and Procedure (CAAIP) or also known as CAP 562 and DoD-HDBK791. The former was used in order to have better illustrations and DoD-HDBK-791 was used to understand the design criteria..

\section{Results and Discussions}

In this section, the author described the second stage of the maintainability allocation process. In this stage a more accurate MTTR value is used based on the maintainability prediction results to check the allocation method. The second stage utilises the MTTR calculated from the maintainability prediction results above shown in Table 5. In addition, the second stage is utilised for the purpose of comparison as to identify the accuracy of prediction. The result of the maintainability allocation is shown in Table 5. 
Table 5 Maintainability Allocation base on MTTR= 0.53

\begin{tabular}{|c|l|c|}
\hline No & \multicolumn{1}{|c|}{ Components } & $\begin{array}{c}\text { Maintenance Allocation Time } \\
\text { MTTR }=0.53 \text { hour }\end{array}$ \\
\hline 1 & Actuator & 0.45 \\
\hline 2 & Antiskid & 0.45 \\
\hline 3 & Brake & 0.7 \\
\hline 4 & Brake Assembly & 0.57 \\
\hline 5 & Connector & 0.45 \\
\hline 6 & Control Unit & 0.4 \\
\hline 7 & Hydraulic & 0.45 \\
\hline 8 & Proximity Sensor & 0.6 \\
\hline 9 & Proximity Switch & 0.6 \\
\hline 10 & Selector Valve & 0.45 \\
\hline 11 & Sensor & 0.5 \\
\hline 12 & Steering & 0.6 \\
\hline 13 & Structure & 0.6 \\
\hline 14 & Strut & 0.6 \\
\hline 15 & Switch & 0.45 \\
\hline 16 & Tire & 0.6 \\
\hline 17 & Uplock Switch & 0.45 \\
\hline 18 & V-Belt & 0.6 \\
\hline 19 & Warning Light & 0.45 \\
\hline 20 & Warning Systems & 0.6 \\
\hline 21 & Wheel & 0.6 \\
\hline 22 & Wire & 0.45 \\
\hline 23 & Wire Harness & 0.45 \\
\hline & & \\
\hline
\end{tabular}

The list of components as collected from the SDR analyses. All listed components are received the most reports of SDR. As results, Table 6 show the summary for both MTTR values and both results are illustrated in Figure 6. Both MTTR show almost the same trendlines.

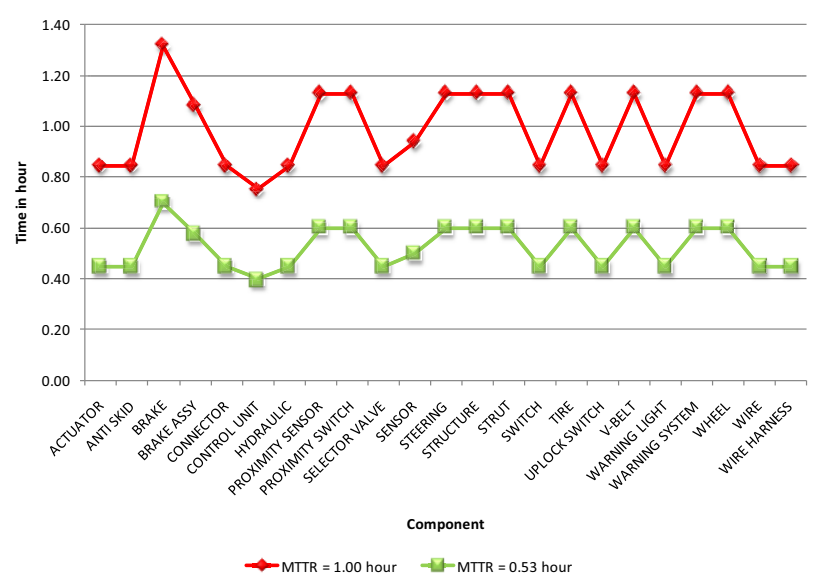

Figure 6 The trend of maintainability allocation times for both MTTR values for BAe 146 - 300 Landing Gear
Table 6 The summary of maintainability allocation for BAe $146-300$ for both MTTR values.

\begin{tabular}{|c|l|c|c|}
\hline \multirow{2}{*}{ No Components } & \multirow{2}{*}{} & \multicolumn{2}{|c|}{ Maintenance Allocation Time in hour } \\
\cline { 3 - 4 } & & MTTR $=1.00$ hour & MTTR $=0.53$ hour \\
\hline 1 & Actuator & 0.85 & 0.45 \\
\hline 2 & Antiskid & 0.85 & 0.45 \\
\hline 3 & Brake & 1.32 & 0.7 \\
\hline 4 & Brake Assembly & 1.08 & 0.57 \\
\hline 5 & Connector & 0.85 & 0.45 \\
\hline 6 & Control Unit & 0.75 & 0.4 \\
\hline 7 & Hydraulic & 0.85 & 0.45 \\
\hline 8 & Proximity Sensor & 1.13 & 0.6 \\
\hline 9 & Proximity Switch & 1.13 & 0.6 \\
\hline 10 & Selector Valve & 0.85 & 0.45 \\
\hline 11 & Sensor & 0.94 & 0.5 \\
\hline 12 & Steering & 1.13 & 0.6 \\
\hline 13 & Structure & 1.13 & 0.6 \\
\hline 14 & Strut & 1.13 & 0.6 \\
\hline 15 & Switch & 0.85 & 0.45 \\
\hline 16 & Tire & 1.13 & 0.6 \\
\hline 17 & Uplock Switch & 0.85 & 0.45 \\
\hline 18 & V-Belt & 1.13 & 0.6 \\
\hline 19 & Warning Light & 0.85 & 0.45 \\
\hline 20 & Warning Systems & 1.13 & 0.6 \\
\hline 21 & Wheel & 1.13 & 0.6 \\
\hline 22 & Wire & 0.85 & 0.45 \\
\hline 23 & Wire Harness & 0.85 & 0.45 \\
\hline & & & \\
\hline
\end{tabular}

\section{Conclusions}

The existing maintainability allocation methodology has been improved by the author. The improved methodology is performed by adding more modules and score values related to mechanical aircraft components (i.e. Landing Gear, Mechanical parts). The additional modules and score values have been tested and validated by using several case studies (i.e. Fuel System and Communication Systems).

The additional modules have been assigned to specific score values. The improved methodology, testing and validation results have been described in section 4.3. The linear formula, as shown below, has been chosen as the primary formula to calculate the new score values for new modules and shown in equation (1).

$$
y=1.4364 x+1.769
$$

Furthermore, to ensure the development methodology and improved approach is applicable to industry, the selected approved aircraft has been used for further testing and validation processes. The case studies have been tested and validated in accordance with the approved maintenance manual supplied by a certified aircraft Maintenance and Repair Organisation (MRO). Overall, the results are very successful.

\section{References}

1. Federal Aviation Administration (FAA), Service Difficulty Reports, available at: http://avinfo.faa.gov/dd sublevel.asp?Folder $=\% 5 \mathrm{CSDRS}$ (accessed April, 13), 2011 
2. Federal Aviation Administration, Service Difficulty Reports, available at: http://www.faa.gov/data research/aviation data s tatistics/data downloads/ (accessed August, 8), 2010.

3. Mahar, D., Fields, W., Reade, J., Zarubin, P. and McCombie, S., Nonelectronic Parts Reliability Data - 2011, 2011; Reliability Analysis Center (RAC).

4. MIL-HDBK-472, Maintainability Prediction, MIL-HDBK-472, 1966; Department of Defense, Washington, DC.

5. DOD-HDBK-791, Maintainability Design Techniques, 1988; DOD-HDBK-791, Department of Defense, USA.

6. Civil Aviation Authority, Civil Aircraft Airworthiness Information and Procedures (CAAIP), 2008; CAP 562, CAA, UK.

7. Chipchak, J. S., "A Practical Method of Maintainability Allocation", Aerospace and Electronic Systems, IEEE Transactions. 1971, vol. AES-7, no. 4, pp. 585-589. 